\title{
Fruit-Growing and Research.
}

THE application of scientific methods and principles is steadily gaining ground in fruit culture as in other branches of agriculture, and the numerous publications on the subject provide evidence of a widening interest in the matter, both as regards the scientific and the practical worker.

The earlier work of Spencer Pickering and the Duke of Bedford stimulated interest in the root systems of fruit trees, and at Long Ashton ${ }^{1}$ the matter of root development under various conditions is being followed up. It appears that the method of treatment at the time of planting has little effect on the type of root produced, a new root system being derived from the collar region of the tree and little growth occurring elsewhere; aeration is considered to be a dominant factor in determining the actual point of origin of the new roots. Root formation and growth are most active at the beginning and towards the end of the season, the greatest increase in root length occurring during the latter period, at the time when shoot growth is rapidly decreasing. Other experiments deal with the extension of the root system throughout the soil, a matter which has a direct bearing on the degree of overlapping of roots when too close planting is practised.

On the pathological side special attention has been directed to leaf-scorch on fruit trees, and the trouble has been found to be due to various causative agents. Among the chief of these are unfavourable soil conditions, due to deficient food or water supply or to defective aeration owing to the mechanical character of the soil. Scorching is also attributed to the direct action of wind, to excessive heat falling on the leaf, or to injury to the vascular system of the plant, such as may be caused by ringing or by the presence of a fungus which penetrates the vascular tissue and interferes with the water supply to the leaves.

The importance of spraying to combat disease is now widely recognised, and at East Malling ${ }^{2}$ direct 1 Annual Report of the Agricultural and Horticultural Research Station, Long Ashton, 1921.

2 Grubb, N. H. (rg2I), Journal of Pomology, II., No. 2. experimental work is being carried out with fungicides on apple trees. Every fungicide tested reduces apple scab (Venturia incqualis), though the degree of effectiveness varies, Bordeaux mixture usually proving the best. Generally speaking, the crop and the size of the fruit are improved by spraying, with certain. exceptions, and there are indications that summer spraying may improve the keeping quality of the fruit by reducing attacks of brown-rot (Sclevotinia fructigens). An interesting point is that the effects of spraying are cumulative, sprayed trees being less heavily affected in the succeeding years.

A critical examination of the stocks used for stone fruits ${ }^{3}$ shows that little or no attempt has hitherto been made to group them as has been done for those used for apples and pears, rapidity of growth and general availability being usually the deciding factors in the selection of stocks in any particular instance. The descriptions worked out at East Malling are the beginnings of an attempt to set up a permanent standard of classification and identification with the view of the ultimate improvement of stone fruit cultivation.

In an interesting survey on progress in methods of practical fruit-growing in the Journal of the Royal Agricultural Society of England, ${ }^{4}$ the whole business, from the selection of a holding to the final packing of the fruit, is traced. Laying out and planting the fruit farm, raising and selecting trees, pruning, manuring, diseases, and pests are all brought under consideration in a way that provides suggestive reading for all interested in the subject, and its value is enhanced by a useful bibliography. In this connexion also attention may be directed to the collected leaflets ${ }^{5}$ on fruit recently reissued by the Ministry of Agriculture, in which various problems the practical fruit-grower encounters in his work receive detailed consideration.

3 Hatton, H. G. (r92r), Journal of Pomology, II., No. 4.

5 Collected Leaflets on Fruit, I92r. Sectional volumes, No. 4. Ministry of Agriculture and Fisheries.

\section{Volcanic Activity in Nigeria.} N NATURE of July 15, p. 97, an account was given
of volcanic activity in Nigeria during MarchMay last. The following extracts, from the reports of Mr. H. S. Cameron, acting Supervisor of Plantations in Nigeria, furnish some later information. They are placed at our disposal through the courtesy of the Colonial Office :-

On June $I_{7}$ the manager of Bibundi informed me by telephone that lava streams had commenced to flow again; also that heavy damage was being done by floods. On June 18 I went to Bibundi, and going by trolley to Dollmanshöhe I found the roadway of the bridge entirely swept away by floods and also one of the four piers gone. I went up the river, and after about a mile reached the first flow of lava, which had been advancing the day before but had now cooled and was stationary. Crossing from there to Wernerfelde, progress was shortly prevented by advancing lava; the stream here was molten, but its advance, which was more "creeping" than "flowing," was over a very wide area and on a gentle slope, and it seemed probable that eventually it would cool and turn the main lava stream down the old course of the Njonge river and extend into the sea, as part of the flow was then doing.
The flooding damage was considerable and I think unpreventable; the amount of water is so great that it is impossible to direct it. More than fifty inches of rain fell in the first seventeen days of June, and the water from an area which formerly fed three rivers and part of a fourth has now no channel: not only is an exit lacking, but rain falling on lava does not sink in and percolate through but rushes at once to the lowest level, so free drainage is more necessary than ever.

On June $22 \mathrm{I}$ received a letter stating that the lava had broken through near Dollmanshöhe bungalow, followed the course of the stream, and was threatening the hospital, which had been abandoned. On reaching the bridge-end at Dollmanshöhe on June 25, I found that the whole of that division above the iron road had been covered with lava, and cascades of molten lava were flowing down the banks of the ravine. It was really a wonderful sight. The river bed was full of detached flows of lava fed from the Dollmanshöhe plateau, where it had been massing during the past week. I inspected the whole length from near the Thormählenfelde bungalow to the director's house, finding flowing lava everywhere. By afternoon the ravine was filled, and by II P.M. the lava had crossed the rail where the Government road turns

NO. 2762 , VOL. I IO] 
off and was advancing down the latter and towards it from various points along the river course on the left.

Owing to the steady progress between June 18 and 25 , and the rapid flow on the latter date, I considered it advisable to order the removal of all the machinery and the salving so far as possible of all building materials worth removing from machine house, cacao house, hospital, and director's house.

On July II I again visited Bibundi. The lava had advanced considerably since June 25 , but its activity is gradually dying out, though the lava streams from the crater, so far as can be seen in this very misty weather, continue as strong as ever. Probably there will be another period of rest and banking up to be followed by a further advance, and everything points to this following the line of the iron road and Government road to the cacao store and machine house, and possibly breaking through the main portion of Thormählenfelde to the Ninonne River higher up.

On July I $5_{5}$ the manager of Bibundi reported : "The main lava stream is quiet; but for the last three nights I have seen a large new stream coming down the mountain. It is very bright and much closer to this side than before."

\section{The Royal Photographic Society's Exhibition.}

THE Annual Exhibition of the Royal Photographic Society at 35 Russell Square remains open until October 28. Admission is free. The natural history section of the scientific and technical division has improved considerably in recent years. There are still a good many single photographs of an animal, a flower, or an insect that have no particular interest, or if they have it is not indicated; but there are many series showing progressive changes, such as Dr. S. Hastings's nine illustrations of soil formation in the Alps, in which he shows the bare rock covered at first with crustaceous lichens, and traces the stages of vegetation until an alpine meadow is produced. Other series show many varieties of the same kind of thing, as Mr. C. H. Caffyn's thirty sections of calcareous, arenaceous, and igneous rocks, and Dr. Rodman's animal and vegetable hairs. With scarcely any exception the photography in this section is excellent.

Among the "Technical Applications of Photo. graphy " Dr. J. S. Plaskett shows four photographs taken at the focus of the 72 -inch reflecting telescope at the Dominion Astrophysical Observatory, Victoria, B.C., which also give evidence of the accuracy of figure of the mirror. The Mount Wilson Observatory, Carnegie Institution of Washington, contributes specimens of the work of the Ioo-inch Hooker reflector and of the 6o-inch reflector, as well as photographs of the unusual spectra of seven stars, made with these instruments. Enlarged negative prints of a latitude variation plate and a wave-length plate are among the exhibits of the Astronomer Royal, Greenwich.

The production of accurate comparative scales by photographic means is fully described and illustrated by Mr. A. E. Bawtree, and Mr. Wilfred Mark Webb shows how, by chemical and photographic means, a Russian internal passport was made to yield deleted details which showed that the document had done duty on four separate occasions for as many different persons.

Mr. G. A. Clarke illustrates upper cloud formations which support the theory of Prof. Bjerknes that depressions have their origin in the meeting of a warm, moist, equatorial current and a cold, dry, polar current. Cloud formation and structure is shown from the upper side by Mr. F. W. Baker,

There are many exhibits that deal with the technicalities of gelatine plate manufacture and the statistical properties of plates by workers in America, as well as in this country. We may refer specially to the beautiful photomicrographs of silver bromide crystals, at 3000 diameters, by Mr. A. P. H. Trivelli, and the characteristic curves of modern high-speed dry plates with photomicrographs of the grains that constitute the sensitive material by Mr. J. W. Grundy. Mr. Grundy also contributes a fine series of photographs taken under various conditions from a height of about I4,000 feet.

Among numerous radiographs by several workers the effect of the Potter-Bucky diaphragm is shown by Mr. R. B. Wilsey. This diaphragm consists of a grid made of parallel strips of lead foil, the planes of which are in line with the direction of the radiation from the tube. It is placed between the patient and the film, and moved during the exposure so that it may not show on the radiograph; it absorbs a large proportion of the scattered rays.

There is a large collection of colour transparencies, and among them some of scientific interest, but the most remarkable are the stereoscopic slides made on autochrome plates by Mr. S. Pegler. The successful reproduction of the colour and the brilliancy of silver plate, various articles of jewellery, and coloured stones, together with the realistic appearance, demonstrates possibilities of this method that are little known.

C. J.

\section{University and Educational Intelligence.}

LONDON.-The senate of the university includes sixteen members elected by registered members of convocation and sixteen by the faculties. Of the former, six are elected by the registered graduates in science; and of the latter, the faculty of science appoints four. There are two vacant seats in science, and five candidates have presented themselves as candidates for them. The candidates are: Dr. George Senter, principal of Birkbeck College, and author of a number of papers and other works on chemistry (Dr. Senter is a member of the faculty of science, and is therefore eligible for election as a representative of the faculty in the senate); $\mathrm{Mr}$. T. Ll. Humberstone, an old student and associate of the Royal College of Science, well known to be particularly familiar with the work of the University and educational problems generally; Dr. Jessie White, who is especially interested in methods of teaching science; Dr. J. S. Bridges, director of education, Willesden; and Mr. C. W. Crook, headmaster, Central Secondary School, Wood Green. The poll closes on Tuesday next, Oct. Io, and it is hoped that graduates will not fail to send in their voting papers before that date.

ST. Andrews.-The honorary degree of LL.D. was conferred upon the Prince of Wales on September 28. In an address to his Royal Highness after the presentation, Dr. J. C. Irvine, principal of the university, reminded him that St. Andrews was not only a place of beauty and the home of a noble game, but also a centre from which great movements had sprung and powerful influences had spread far and wide. The ancient university was ever ready to enlarge its activities, blending the wisdom of the past with the spirit of progress. 